\title{
Factors Affecting Fault Tolerance during Load Balancing in Cloud Computing
}

\author{
Bidush Kumar Sahoo ${ }^{1}$, Srikanta Kumar Mohapatra ${ }^{2 *}$, Premananda Sahu ${ }^{3}$, Anupam Baliyan ${ }^{4}$, Vikas \\ Solanki $^{5}$
}

1, 2.3,4,5 Chitkara University Institute of Engineering and Technology, Chitkara University, Punjab, India

* Corresponding author's Email: srikanta.mohapatra@ chitkara.edu.in

\begin{abstract}
:
Cloud computing is built upon the advancement of virtualization and distributed computing to support cost-efficient usage of computing resources and to provide on demand services. After methodical analysis on various factors affecting fault tolerance during load balancing is performed and it is concluded that the factors influencing fault tolerance in load balancing are cloud security, adaptability etc. in comparatively more software firms. In this paper, we have created a model for various IT industries for checking the fault tolerance during Load balancing. An exploration is done with the help of some renowned IT farms and industries in South India. This work consists of 20 hypotheses which may affect the fault tolerance during load balancing in South India. It is verified by using potential statistical analysis tool i.e. Statistical Package for Social Science (SPSS).
\end{abstract}

Keywords: Load Balancing, Fault Tolerance, Cloud SIM, SPSS, AWS

\section{Introduction}

All manuscripts must be in English. Cloud computing paradigm has been widely adopted due to the increasing demand for flexibility and scalability in dynamically obtaining and releasing computing resources in a cost-effective and device-dependent manner [1]. It helps in hosting applications without the burden of installation and maintenance.

In the current era of web application in cloud computing plays a vital role in opening the various possibilities for determining the quality of service in businesses and non businesses clients. As service to the client through various application is a trend for modern enterprises, so the business client provide out sourcing through different external data centre. For an example Amazon, Google, Yahoo \& many other service providers are able to outsource their recourses through the manageable data centre [2,3]. So for the service provider the need of fault tolerance in cloud service is a key factor to be considered.

The remainder of the paper is organized as follows. The section 2 represents the related work done in the proposed research area. Background Study related to fault tolerance during load balancing is provided in section 3. Section 4 describes the proposed model. Implementation details and results have been defined in section 5. Finally concluding remarks and future work has been given in section 6 .

\section{Related Work}

According to Rodrigo, the role of quality of service and load pattern in cloud computing varies from time to time [4]. The application service posting in cloud computing model has particular composition, development, requirement and provisioning facilities. Evolution of cloud computing policies the workload model energy source performance plays a vital role for overcoming the issues related to proper configuration can be judged by Cloud SIM tool kit. These two kits suppose the behaviour of the model in the data centre which different virtual machines. It eases the pressure of inter network cloud and single cloud. The energy management system inter centres plays a vital role in cloud research providing. Therefore the Cloud SIM tool kit helps in application service providers for improvising the quality of service.

According to Sheng, the prediction of load in cloud computing system is very critical for achieving a proper quality of service [5]. For accuracy and prediction you can go for Baye's model for predicting the mean load for a long term interval. It also provides the efficient combination of the given features. The experiment using Baye's method achieves highest accuracy with significantly less error.

According to Lizheng, the development of cloud computing environment is based on quality of service along with the optimized performance [6]. For optimizing the performance in cloud computing parameters of 
services in data centres is taken so by analyzing through the performance parameter the optimization mode function is created. It compares with another simulation results and queuing system.

By Michel Ambrust, the developers use the internet services not only for providing the data centre services but also it is concerned with the provision in the accurate potential customers with the required quality of service [7]. In cloud computing environment data centres are more concerned with the performance of data shifting from one client to another as it is used in licensing model.

According to Almeida, quality of service is prime Minister in evaluating service self management techniques and resource allocation to the clients. Resource allocation is the prime component in the service level agreements [8]. The self management techniques which check the resource allocation along with control optimization issues are the key factors in the quality of service. The joint resource allocation is a noble technique for finding the workloads and checking with alternative methods.

According to Ardangna, the quality of service management gives assurance to various level of performance reliability with availability issues [9]. The quality of service in cloud computing environment may not provide homogeneous allocation of resources. So, get a new direction for investigating the self management methods of quality of service. The quality of service model is applicable to the cloud computing environment during the resource management.

According to Faisal, in cloud computing the services of end to end users gives better service in comparison with demanded obligations [10]. The various transaction in network theory cloud computing environment helps in communication the various deployed network slots. The evolution in cloud computing has gained higher quality in different industries because of its cost efficiency.

According to Wickremasinghe, the advances in cloud computing opens the door for various internet application deployments. The server is not properly utilized using its maximum traffic as different cloud providers are offering different packages according to its data centre location the quality of service can be derived from different service providers [11]. The deployment of application by the service software infrastructure platform places a vital role in configuration of various applications. The software infrastructure also depends on different platforms supporting the configured applications.

\section{Background Study}

The issue of fault tolerance carries various techniques for enabling the system to continue the operation in reduced level rather falling completely.

\subsection{Types of faults}

The available faults in a various service shelters can be

1. Network fault, which may occurs due to packet loss, link failure, destination failure.

2. Physical fault, which may occurs in hardware fault, memory fault or storage issue.

3. Processer fault which may occurs due to operating system corruption.

4. Service expire fault, may occurs when the resources is not availing the scheduled service time.

5. Process fault that occurs due to shortage of resource.

\subsection{Techniques for fault tolerance}

Basically, two methods of fault tolerance techniques in cloud computing.

\subsubsection{Relative fault tolerance}

These types of fault tolerance techniques based on some policies like

A. Checking the restart of systems - It means after allowing to restart from recent checkpoints the efficient task should start after it. In this situation, we need to create different check points for individual data processing.

B. Replication- It means different tasks are copied and executed with different resources for the desired output. The implementation of replication can be verified through had loop or Amazon EC2 verifies.

C. Job migration- The job can be shifted to a new machine for proxy server. The reason behind proxy server is the failure of individual task waiting for migration.

D. S-Guard- The S-Guard Policy is required for recovering the data had loop or Amazon EC2.

E. Retry/Task resubmission- When a job fails to execute from the cloud resource the task needs to be resubmitted again to the same machine or other possible machines. 


\subsubsection{Proactive fault tolerance}

These types of failures refer to predict the future component to be in use for avoiding errors. The two different policies are

A. Self healing- At the time of multiple virtual machine running, the occurrence of failure may affects the smooth running of data transfer.

B. Primitive Migration- In this policy after constant observation, the migration on the feedback loop is constantly monitored.

\subsection{Metrics for Fault Tolerance in Cloud Computing}

The various exiting fault tolerance metrics are

A. Throughput-it basically provides the number of jobs whose task is already done. For any system that throughput should be maximum.

B. Response time-it is basically the time taken by the procedure to execute. The response time always should be minimum.

C. Scalability-the available number of nodes in a particular environment influence the fault tolerance capacity of the algorithm.

D. Performance-the characteristics normally check the efficiency of the prepared system. The performance of any system will be maximum when the response time is minimum and throughput is high.

E. Availability-Availability of a system is proportional to the reliability of the system. Basically it is the probability of an item with functions at the given period of time.

F. Reliability-it means when a system can be utilized by a client its necessity is with the constants of efficiency and satisfaction.

G. Overhead Associatively- The overhead are necessary for tax improvement and evolution of the inter and intra processor communication. The overhead always should be minimized.

H. Usability-it means when a system can be utilized by a client for achieving its necessity is with the constants of efficiency and satisfaction.

I. Cost effectiveness-for any system cost is the vital part to be monitored. If in a project the cost is minimized the effectiveness will increase.

\section{New Metrics for Fault Tolerance}

Some new metrics that may affect the load balancing in cloud computing are:

A. Data security- Cloud security is mixture of registered policies controlling authorities and advanced technologies working together for protecting the cloud-based system along with data and infrastructure. The security characteristics are configured for protecting the customer's privacy as well as the authentication of the other individual users [12].

B. Scaling- Scaling in power computing basically first edition of more processor memory or input output devices with the existing service to make it more powerful .In cloud computing environment it provides additional benefits instead of moving to larger size [13].

C. Performance- Performance in cloud computing is a vital factor in recognizing the overall success with the optimum cost of cloud services full stop it requires a lot of attention by the cloud computing providers and the service consumers [14].

D. Crash Cost-In cloud computing environment the cost of breakdown of public cloud computing environment plays and vital role in deciding the efficiency of the service provider. It also affects estimating the cost of cloud computing services [15].

E. Adaptability-Computing environment should be adaptable by nature as customer client's requirement varies from time to time. Cloud computing environment offers the facilities of virtual storage capacity which is rate of high performance to the typical hard disk drive [16].

F. Deadline of work- In cloud computing environment the deadline constraint workflow is a most is the scheduling of processes are provided to various types of clients. The cost deadline based task scheduling is done in cloud computing environment to fulfil the client's needs what is a common scenario this type of algorithm are quite complicated as the deadline varies from client to client [17].

G. Encryption- It is high degree of adjectives on a positive impact in load balancing of cloud computing environment [18]. 
H. Confidentiality- Confidentiality is a factor in load balancing of fault tolerance which decides the sanity of data [19].

I. Unauthorized Access- Under security point of view unauthorized access is also a factor in checking the fault tolerance using during load balancing in cloud environment [20].

J. Cloud control ability-load available in cloud should be having the control ability within it for finding the fault in the environment [21].

H. Energy efficiency- Cloud computing environment check the load to be balanced in the environment [22].

I. IT resource- It resource is the measures support for load balancing in cloud computing environment [23].

\section{Research Methodology}

The research methodology is constituted with the research model and research mechanism applied for questionnaire development along with the analysis methods.

\subsection{Research Model}

The various hypothesis related to affecting characteristics are given in Table 1.

Table 1. Definition Various Hypothesis regarding fault tolerance in Load balancing

\begin{tabular}{|c|c|c|}
\hline Sl.No & Variable & Description \\
\hline H1 & Data Security & $\begin{array}{l}\text { Data Security has a positive impact on fault tolerance during Load } \\
\text { balancing. }\end{array}$ \\
\hline $\mathrm{H} 2$ & Scaling & Scaling has a positive impact on fault tolerance during Load balancing. \\
\hline $\mathrm{H} 3$ & Performance & $\begin{array}{l}\text { Performance has a positive impact on fault tolerance during Load } \\
\text { ncing. }\end{array}$ \\
\hline $\mathrm{H} 4$ & Crash Cost & $\begin{array}{l}\text { Crash Cost has a negative impact on fault tolerance during Load } \\
\text { balancing. }\end{array}$ \\
\hline H5 & Adaptability & $\begin{array}{l}\text { Adaptability has a positive impact on fault tolerance during Load } \\
\text { balancing. }\end{array}$ \\
\hline H6 & Deadline of work & $\begin{array}{l}\text { Deadline of work has a positive impact on fault tolerance during Load } \\
\text { balancing. }\end{array}$ \\
\hline $\mathrm{H} 7$ & Encryption & $\begin{array}{l}\text { Encryption has a positive impact on fault tolerance during Load } \\
\text { balancing. }\end{array}$ \\
\hline H8 & Confidentiality & $\begin{array}{l}\text { Confidentiality has a negative impact on fault tolerance during Load } \\
\text { balancing. }\end{array}$ \\
\hline H9 & $\begin{array}{l}\text { Unauthorized } \\
\text { Access }\end{array}$ & $\begin{array}{l}\text { Unauthorized Access has a negative impact on fault tolerance during } \\
\text { Load balancing. }\end{array}$ \\
\hline H10 & Energy efficiency & $\begin{array}{l}\text { Energy Efficiency has a positive impact on fault tolerance during Load } \\
\text { balancing. }\end{array}$ \\
\hline H11 & IT resource & $\begin{array}{l}\text { IT resource has a positive impact on fault tolerance during Load } \\
\text { balancing. }\end{array}$ \\
\hline
\end{tabular}

\subsection{Research Mechanism}

The Questionnaire development for the metrics that affects the fault tolerance during the load balancing in cloud computing are supplemented by various type of questions like multiple choice and short question with 5 point scale for gathering data on different metrics. Through this question are the primary data is collected from our research work using the convenience sampling technique which is suiting for our data. The component sampling technique is unknown prospective sampling technique which decides suitability convenient to all the researchers [24].

The respondents are classified into four broad categories like administrative staff software developer's clients and testers. The physical questionnaire and the question are generated by the Google form is utilized for data collecting. 


\subsubsection{Questionnaire Development Strategy}

The question are generated by using the metrics which may impact the load balancing strategy in cloud computing. The data collected from different respondents to various industries. All kinds of respondents are there starting from testers to the administrative staffs [25].

\subsubsection{Analysis method}

The data analysis work is done by the statistical analysis SPSS for finding the various status regarding the given data. We have considered 20 metrics for finding various outcomes related to the utilization of factors [26]. It uses T test, ANOVA test 4 correlations and regression analysis along with that validity testing. The conceptual model is provided in Figure. 1.

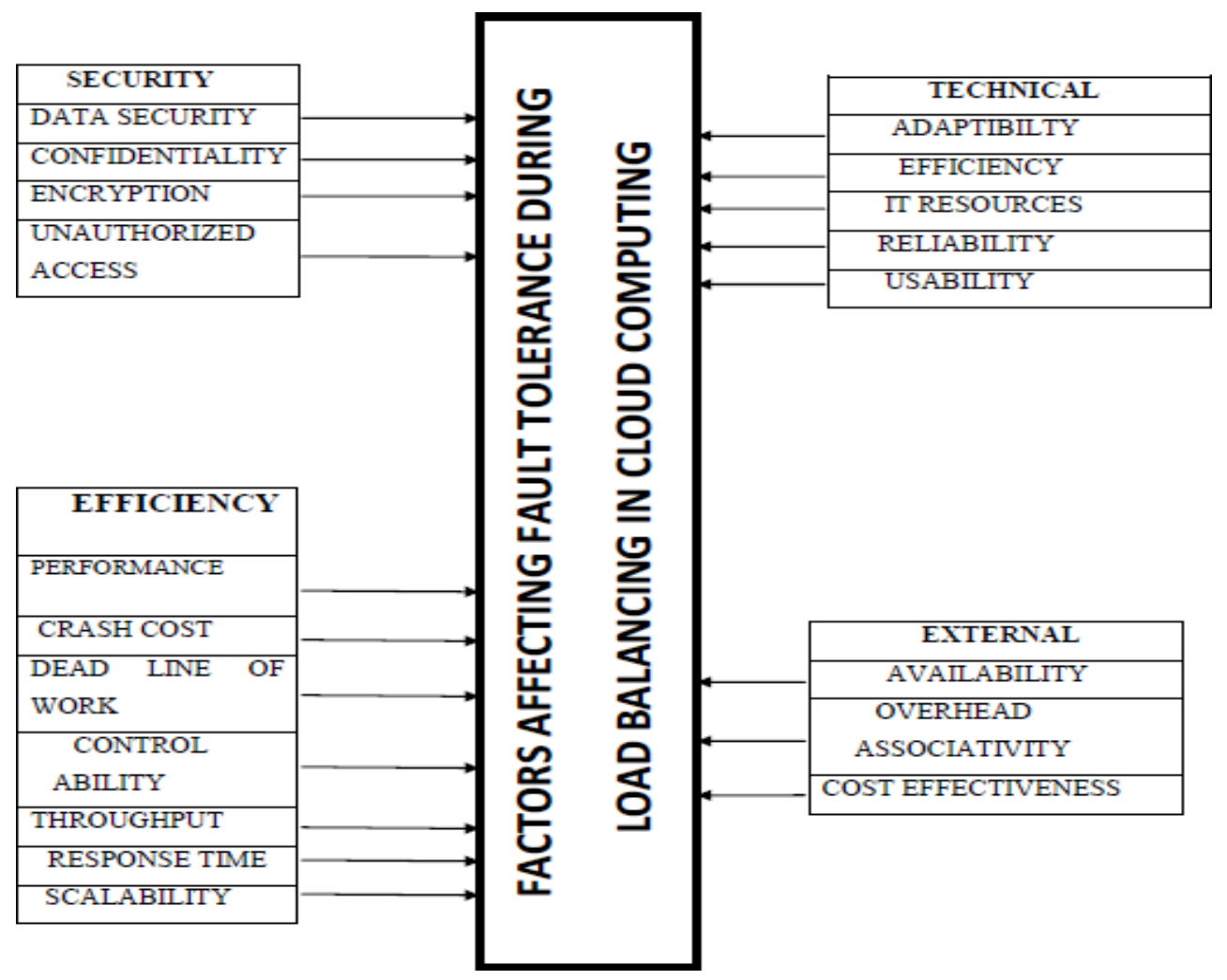

\section{Result Analysis}

Figure. 1 Conceptual Model

The work is purified and analyzed using the SPSS tool when the results of verification are provided in the below mentioned tables

\subsection{Basic Analysis}

The statistical analysis of individual metrics is done by SPSS for checking the reaction and configuration of load balancing in cloud computing. The questionnaire is developed and verified properly. It is distributed among 986 contributors. The questions involve barriers closed questions and 5 point liker scale questions for getting the various replies from different contributors [27]. The questionnaire was almost all the characteristics which can be used for the long balancing in cloud computing.

\subsection{Analysis regarding fault tolerance in load balancing}

Different contributors provide their suggestion in close question format and in multiple option formats. 933 output for checking the fault tolerance in load balancing for cloud computing environment. The output analysis is depicted in Table 2. 
Table 2. Respondent's Analysis

\begin{tabular}{|l|l|c|c|c|c|}
\hline S1. No. & Variable & Mean & S.E. & S.D. & Y/N(960) \\
\hline H1 & Throughput & 0.75 & .011 & 0.33 & $767 / 193$ \\
\hline H2 & Response Time & 0.69 & .015 & 0.39 & $696 / 264$ \\
\hline H3 & Scalability & 0.77 & .012 & 0.41 & $785 / 175$ \\
\hline H4 & Performance & 0.83 & .016 & 0.31 & $734 / 226$ \\
\hline H5 & Availability & 0.81 & .009 & 0.44 & $676 / 284$ \\
\hline H6 & Reliability & 0.67 & .014 & 0.37 & $706 / 254$ \\
\hline H7 & Overhead associatively & 0.84 & .008 & 0.34 & $657 / 303$ \\
\hline H8 & Usability & 0.87 & .007 & 0.43 & $721 / 239$ \\
\hline H9 & Cost Effectiveness & 0.73 & .017 & 0.36 & $735 / 225$ \\
\hline H10 & Data Security & 0.83 & .016 & 0.31 & $734 / 226$ \\
\hline H11 & Scaling & 0.81 & .009 & 0.44 & $676 / 284$ \\
\hline H12 & Performance & 0.67 & .014 & 0.37 & $706 / 254$ \\
\hline H13 & Crash Cost & 0.84 & .008 & 0.34 & $657 / 303$ \\
\hline H14 & Adaptability & 0.87 & .007 & 0.43 & $721 / 239$ \\
\hline H15 & Deadline of Work & 0.83 & .016 & 0.31 & $734 / 226$ \\
\hline H16 & Encryption & 0.81 & .009 & 0.44 & $676 / 284$ \\
\hline H17 & Confidentiality & 0.67 & .014 & 0.37 & $706 / 254$ \\
\hline H18 & Unauthorized Access & 0.67 & .014 & 0.37 & $706 / 254$ \\
\hline H19 & Energy Efficiency & .008 & 0.34 & $657 / 303$ \\
\hline H20 & IT resources & .007 & 0.43 & $721 / 239$ \\
\hline
\end{tabular}

Before testing any hypothesis it is necessary to check the reliability and validity of that hypothesis. Using SPSS tool the structural equation model is created along with the outcomes of reserved and provided in table 3.The reserved epics through Cronbach's alpha algorithm that reliability above point 7 and the variance above 0.5 is allowed.

So if matrix is statistically valid and reliable. Then it can be concluded that the above reliability and validity test are utilized for checking the metrics [28]. It is verified the earth the results are above Court of values.

\subsection{T test Analysis}

After performing the reliability and validity test using SPSS checking the hypothesis is the next part. Now for identifying the effect of metrics load balancing test is used by the questionnaires for finding the effect of fault tolerance in load balancing Table for provides the result where it is shown that the $\mathrm{p}$ value is lower than 0.05 and its $t$ value is above 1.96 for degree level [29].

Table 3. Summarization of structural equation model

\begin{tabular}{|l|l|l|c|}
\hline Variables & Cronbach's $\alpha$-Test & C.R. & Average Variance \\
\hline
\end{tabular}




\begin{tabular}{|l|c|c|c|}
\hline Security & 0.9478 & 0.9481 & 0.7192 \\
\hline Technical & 0.9324 & 0.9281 & 0.6652 \\
\hline Efficiency & 0.9225 & 0.9377 & 0.6769 \\
& & & 0.8183 \\
\hline External & 0.9549 & 0.9483 & \\
\hline
\end{tabular}

It also provides the knowledge that there metrics can we able to feature in the fault tolerance during the load balancing in cloud computing environment. For equality testing L-test and T-test is done and the results are shown in Table 4.

Table 4. L-Test and T-test for equality

\begin{tabular}{|l|l|l|l|l|}
\hline \multirow{2}{*}{ Variable } & L-Test & Sig & T & Df \\
\cline { 2 - 5 } & F & .005 & 155.245 & 128 \\
\hline Throughput & 13.158 & .002 & 15.987 & 225 \\
\hline Response Time & 11.267 & & & \\
\hline Scalability & & .003 & 171.234 & 316 \\
\hline Performance & 495.85 & .007 & 28.438 & 294 \\
\hline Availability & 4.397 & .007 & 59.238 & 169 \\
\hline Reliability & 3.65 & .003 & 78.234 & 113 \\
\hline Overhead associatively & 71.88 & .001 & 123.977 & 438 \\
\hline Usability & 39.178 & & & \\
\hline Cost Effectiveness & & .006 & 29.345 & 228 \\
\hline Data Security & 165.87 & .001 & 173.912 & 339 \\
\hline Scaling & 23.888 & & & \\
\hline Performance & & .003 & 21.963 & 172 \\
\hline Crash Cost & 139.406 & .005 & 166.456 & 228 \\
\hline Adaptability & 216.389 & .005 & 73.987 & 438 \\
\hline Deadline of Work & 22.485 & .001 & 19.937 & 268 \\
\hline Encryption & 12.875 & .004 & 144.345 & 432 \\
\hline Confidentiality & 173.458 & .003 & 39.567 & 231 \\
\hline Unauthorized Access & 32.964 & & & \\
\hline Energy Efficiency & & .002 & 123.094 & 142 \\
\hline IT resources & 37.128 & .001 & 33.345 & 543 \\
\hline & 28.519 & .006 & 177.098 & 189 \\
\hline
\end{tabular}




\subsection{Regression Analysis}

Table 5. Summarization of Factor analysis

The relationship between various Independent and dependent metrics is visualized through the regression analysis the linear regression is used in this work for checking their relationship among the independent and dependent metrics [30]. The outcome of regression analysis is provided in Table 5. It is relevant to say that the most valuable information taken by the result of SPSS source the significance individual predicting metrics.

\begin{tabular}{|c|c|c|c|c|c|c|c|c|c|}
\hline \multirow[t]{2}{*}{ Factors } & \multicolumn{2}{|c|}{$\begin{array}{l}\text { Model } \\
\text { Summary }\end{array}$} & \multicolumn{2}{|c|}{ ANNOVA } & \multicolumn{2}{|c|}{$\begin{array}{l}\text { Unstandardized } \\
\text { Coefficient }\end{array}$} & \multirow[t]{2}{*}{$\begin{array}{l}\text { Standardized } \\
\text { Coefficient }\end{array}$} & \multirow[t]{2}{*}{$\mathbf{T}$} & \multirow[t]{2}{*}{ Sig.t } \\
\hline & $\begin{array}{l}\text { Multiple } \\
\mathrm{R}\end{array}$ & $\overline{\mathrm{R}^{2}}$ & $\mathrm{~F}$ & $\begin{array}{l}\text { Sig. } \\
\text { F }\end{array}$ & B & $\mathrm{SE}$ & & & \\
\hline Throughput & 0.783 & 0.679 & 3752.673 & .000 & .764 & 0.021 & 0.783 & 75.432 & 0.000 \\
\hline Response Time & 0.896 & 0.953 & 11835.867 & .000 & 0.875 & 0.011 & 0.896 & 117.075 & 0.000 \\
\hline Scalability & 0.623 & 0.376 & 567.345 & .000 & 0.547 & 0.031 & 0.623 & 25.457 & 0.000 \\
\hline Performance & 0.917 & 0.862 & 7945.456 & .000 & 0.895 & 0.023 & 0.917 & 85.456 & 0.000 \\
\hline Availability & 0.867 & 0.692 & 2653.373 & .000 & 0.962 & 0.019 & 0.867 & 53.357 & 0.000 \\
\hline Reliability & 0.758 & 0.624 & 1352.876 & .000 & 0.933 & 0.026 & 0.758 & 29.569 & 0.000 \\
\hline $\begin{array}{l}\text { Overhead } \\
\text { associatively }\end{array}$ & 0.967 & 0.956 & 16785.987 & .000 & 0.958 & 0.013 & 0.967 & 119.045 & 0.000 \\
\hline Usability & 0.496 & 0.268 & 291.876 & .000 & 0.513 & 0.035 & 0.496 & 22.845 & 0.000 \\
\hline $\begin{array}{l}\text { Cost } \\
\text { Effectiveness }\end{array}$ & 0.754 & 0.613 & 1023.876 & .000 & 0.792 & 0.019 & 0.754 & 31.561 & 0.000 \\
\hline Data Security & 0.614 & 0.297 & 512.765 & .000 & 0.657 & 0.028 & 0.614 & 23.271 & 0.000 \\
\hline Scaling & 0.749 & 0.529 & 1284.985 & .000 & 0.813 & 0.019 & 0.749 & 29.784 & 0.000 \\
\hline Performance & 0.658 & 0.427 & 732.347 & .000 & 0.726 & 0.032 & 0.658 & 26.454 & 0.000 \\
\hline Crash Cost & 0.871 & 0.705 & 2786.321 & .000 & 0.932 & 0.023 & 0.871 & 51.367 & 0.000 \\
\hline Adaptability & 0.643 & 0.425 & 714.654 & .000 & 0.595 & 0.018 & 0.643 & 32.987 & 0.000 \\
\hline $\begin{array}{l}\text { Deadline of } \\
\text { Work }\end{array}$ & 0.815 & 0.684 & 3175.345 & .000 & 0.957 & 0.015 & 0.815 & 57.548 & 0.000 \\
\hline Encryption & 0.468 & 0.379 & 617.765 & .000 & 0.479 & 0.011 & 0.468 & 17.876 & 0.000 \\
\hline Confidentiality & 0.572 & 0.463 & 589.376 & .000 & 0.567 & 0.023 & 0.572 & 18.765 & 0.000 \\
\hline $\begin{array}{l}\text { Unauthorized } \\
\text { Access }\end{array}$ & 0.914 & 0.816 & 3267.765 & .000 & 0.916 & 0.009 & 0.914 & 64.568 & 0.000 \\
\hline $\begin{array}{l}\text { Energy } \\
\text { Efficiency }\end{array}$ & 0.764 & 0.675 & 2789.654 & .000 & 0.654 & 0.731 & 0.764 & 67.764 & 0.000 \\
\hline IT resources & 0.438 & 0.385 & 648.652 & .000 & 0.411 & 0.007 & 0.438 & 21.876 & 0.000 \\
\hline
\end{tabular}

\section{Discussion}

Research hypothesis are experimented by using T-test and showed that each hypothesis is statistically important. The Regression Analysis supports the T-tests outcomes and found that the prime features that plays important role in affecting fault tolerance in load balancing are Cloud Security (98\%), Adaptability (97.8\%) and Performance (97.9\%). The lower significant features for cloud adoption are Encryption (51.2\%), IT Resource (49.77\%) and Energy Efficiency (52.8\%). 




Figure. 2 The influence of types of metrics

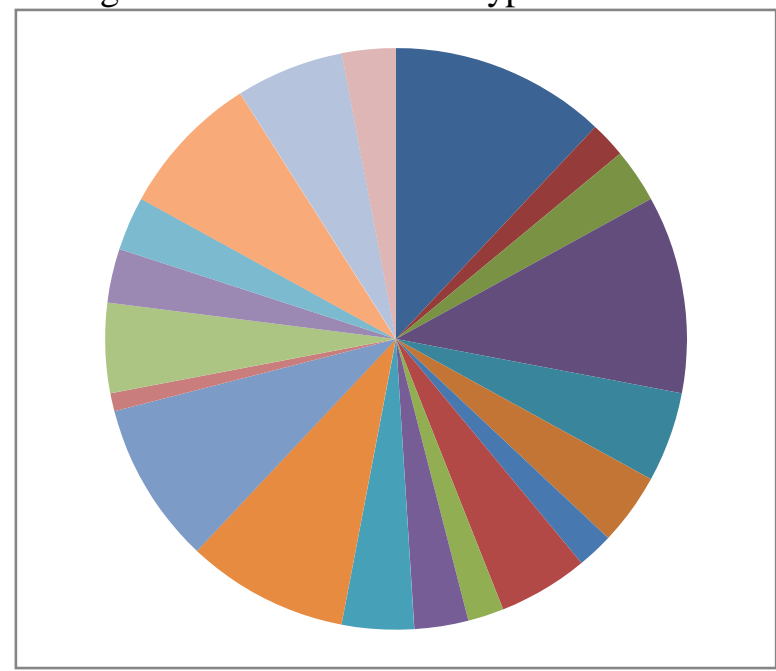

Figure. 3 The metrics affecting Graph

Figure. 2 and Figure. 3 respectively represent the influence of type of characteristics and the various characteristics affecting the fault tolerance in load balancing in cloud computing environment.

\section{Conclusion}

In this study, we have found out the significant features affecting fault tolerance during load balancing supported by present literature and views of the professional IT persons. The present factors along with some new significant features that are unexplored before are integrated for creating the model. It has four perspectives (Security, Technical, Efficiency and External). It is attached with fault tolerance issues. Twenty hypotheses are created against these four perspectives. The model is observed with a sample of 960 IT professionals of reputed IT industries and firms of South India. It is concluded that the factors influencing fault tolerance in load balancing are cloud security, adaptability etc. in comparatively more software firms.

\section{Conflicts of Interest}

This paper is no way related with any organizational financing. It doesn't provide any outcome to any specific industry or personal for its curricular growth.

\section{Author Contributions}

This research article provides idea on the relevant factors affecting fault tolerance during load balancing. In this paper, the authors have utilized many analytical methodologies in order to verify the factor's utility. For validation and analysis it uses SPSS tool, which is provided in the above given tables. All the authors contributed in the analysis, validation and data collection during this article formation.

\section{References}

[1] D. Kliazovich, P. Bouvry, and S.U. Khan, "Green Cloud: a packet-level simulator of energy-aware cloud computing data centers", The Journal of Supercomputing, Vol. 62, No. 3, pp.1263-1283, 2012.

[2] S.H. Lim, B. Sharma, G. Nam, E.K. Kim, and C.R. Das, "MDCSim: A multi-tier data center simulation platform". In 2009 IEEE International Conference on Cluster Computing and Workshops, pp. 1-9, IEEE 2009. 
[3] X. Wang, D. Zhihui, C. Yinong, and L. Sanli, "Virtualization-based autonomic resource management for multi-tier web applications in shared data center", Journal of Systems and Softwar, Vol. 81, No. 9, pp. 1591$1608,2008$.

[4] R.N. Calheiros, R. Ranjan, A. Beloglazov, C.A. De Rose, and R. Buyya, "CloudSim: a toolkit for modeling and simulation of cloud computing environments and evaluation of resource provisioning algorithms", Software: Practice and experience, Vol. 41, No.1, pp. 23-50, 2011.

[5] S. Di, K. Derrick, and C. Walfredo, "Host load prediction in a Google compute cloud with a Bayesian model", In SC'12: Proceedings of the International Conference on High Performance Computing, Networking, Storage and Analysis, pp. 1-11, IEEE 2012.

[6] L. Guo, Y. Tao, Z. Shuguang and J. Changyuan, "Dynamic performance optimization for cloud computing using M/M/m queueing system", Journal of applied mathematics, Vol. 2014, 2014.

[7] M. Armbrust, F. Armando, G. Rean, D.J. Anthony, K. Randy, K. Andy and L. Gunho, "A view of cloud computing", Communications of the ACM, Vol.53, No. 4, pp.50-58, 2010.

[8] J. Almeida, A. Virgílio, A. Danilo, C. Ítalo, F. Chiara and T. Marco, "Joint admission control and resource allocation in virtualized servers", Journal of Parallel and Distributed Computing, Vol.70, No. 4, pp. 344-362, 2010.

[9] D. Ardagna, C. Giuliano, C. Michele, F.P. Juan and W. Weikun, "Quality-of-service in cloud computing: modeling techniques and their applications", Journal of Internet Services and Applications, Vol.5, No. 1, pp.117, 2014.

[10] A. Faisal, C.P. Dorina and C. Murray Woodside, "Network latency impact on performance of software deployed across multiple clouds", In CASCON, pp. 216-229, 2013.

[11] B. Wickremasinghe, N.C. Rodrigo and R. Buyya, "Cloudanalyst: A cloudsim-based visual modeller for analysing cloud computing environments and applications", In 2010 24th IEEE international conference on advanced information networking and applications, pp. 446-452, 2010.

[12] A.A. Soofi, M. I. Khan and F.E. Amin, "A review on data security in cloud computing", International Journal of Computer Applications, Vol.94, No. 5, pp. 12-20, 2014.

[13] K. Mogouie, M.G. Arani and M. Shamsi, "A novel approach for optimization auto-scaling in cloud computing environment", International Journal of Computer Network and Information Security, Vol.7, No. 11, pp. 46-53, 2015.

[14] G. Garrison, L.W. Robin and K. Sanghyun, "The effects of IT capabilities and delivery model on cloud computing success and firm performance for cloud supported processes and operations", International journal of information management, Vol.35, No. 4, pp.377-393, 2015.

[15] Y.M. Essa, "A survey of cloud computing fault tolerance: techniques and implementation" International Journal of Computer Applications, Vol.138, No. 13, pp. 34-38, 2016.

[16] B.K. Sahoo, and M. Ray, "Concurrency testing using symbolic path finder", International Journal of Engineering \& Technology, Vol.7, No. 2.6, pp. 275-282, 2018.

[17] M. Abdel-Basset, M. Mohamed and V. Chang, "NMCDA: A framework for evaluating cloud computing services", Future Generation Computer Systems, Vol.86, pp.12-29, 2018.

[18] P. Kumar and P. J. A. Alphonse, "Attribute based encryption in cloud computing: A survey, gap analysis, and future directions", Journal of Network and Computer Applications, Vol.108, pp.37-52, 2018.

[19] M.G. Jaatun, G. Zhao, A. V. Vasilakos, Å.A. Nyre, S. Alapnes and Y. Tang, "The design of a redundant array of independent net-storages for improved confidentiality in cloud computing", Journal of Cloud Computing: Advances, Systems and Applications, Vol.1, No. 1, pp.1-19, 2012.

[20] Y.A. Hamza, and M. D. Omar, "Cloud computing security: abuse and nefarious use of cloud computing", Int. J. Comput. Eng. Res, Vol.3, No. 6, pp. 22-27, 2013.

[21] T. Omari, G. Franks, M. Woodside and A. Pan, "Efficient performance models for layered server systems with replicated servers and parallel behaviour", Journal of Systems and Software, Vol.80, No.4, pp. 510-527, 2017.

[22] B.K. Sahoo and M. Ray, "Concurrent Bug Detection Using Invariant Analysis", International Journal of Engineering \& Technology, Vol.7, No. 3.4, pp. 6-12, 2018.

[23] J. Zhang, H. Huang and X. Wang, "Resource provision algorithms in cloud computing: A survey", Journal of Network and Computer Applications, Vol.64, pp. 23-42, 2016.

[24] L. Wei, H. Zhu, Z. Cao, X. Dong, W. Jia, Y. Chen, and A. V. Vasilakos, "Security and privacy for storage and computation in cloud computing", Information sciences, Vol.258, pp.371-386, 2014. 
[25] H. Gangwar, H. Date and R. Ramaswamy, "Developing a cloud-computing adoption framework", Global Business Review, Vol.16, No. 4, pp.632-651, 2015.

[26] P. Priyadarshinee, R. D. Raut, M. K. Jha and S. S. Kamble, "A cloud computing adoption in Indian SMEs: Scale development and validation approach", The Journal of High Technology Management Research, Vol.28, No. 2, pp.221-245, 2017.

[27] W.Ting, and Y. Liu "Design and implementation of intelligent accounting data analysis platform based on industrial cloud computing", EURASIP Journal on Wireless Communications and Networking, Vol. 2020, No. 1, pp. 1-8, 2020.

[28] V. Cardellini, E. Casalicchio, V. Grassi and R. Mirandola, "A framework for optimal service selection in broker-based architectures with multiple QoS classes", In 2006 IEEE Services Computing Workshops, pp. 105-112, 2016.

[29] S. Haddd, L. Mokdad, and S. Youcef, "Response time of BPEL4WS constructors", In the IEEE symposium on Computers and Communications, pp. 695-700, 2010.

[30] D. A. Menascé, E. Casalicchio and V. Dubey, "On optimal service selection in service-oriented architectures”, Performance Evaluation, Vol.67, No.8, pp.659-675, 2010. 